\title{
Primary Care Clinicians' Willingness to Care for Transgender Patients
}

\author{
Deirdre A. Shires, PbD, MSW, \\ $M P H^{1,2}$ \\ Dapbna Stroumsa, MD, MPH \\ Kim D. Jaffee, $\mathrm{PbD}, M S W^{4}$ \\ Michael R. Woodford, PbD, MSW \\ 'School of Social Work, Michigan State \\ University, East Lansing, Michigan \\ ${ }^{2}$ Center for Health Policy and Health \\ Services Research, Henry Ford Health \\ System, Detroit, Michigan \\ ${ }^{3}$ Department of Obstetrics and Gyne- \\ cology, Institute for Healthcare Policy and \\ Innovation, University of Michigan, Ann \\ Arbor, Michigan \\ ${ }^{4}$ School of Social Work, Wayne State \\ University, Detroit, Michigan \\ ${ }^{5}$ Lyle S. Hallman Faculty of Social Work, \\ Wilfrid Laurier University, Waterloo, \\ Ontario, Canada
}

Conflicts of interest: authors report none.

\section{CORRESPONDING AUTHOR}

Deirdre A. Shires, PhD, MSW, MPH

School of Social Work

Michigan State University

655 Auditorium Road

122 Baker Hall

East Lansing, MI 48824

shiresde@msu.edu

\begin{abstract}
Transgender patients report negative experiences in health care settings, but little is known about clinicians' willingness to see transgender patients. We surveyed 308 primary care clinicians in an integrated Midwest health system and $53 \%$ responded. Most respondents were willing to provide routine care to transgender patients (85.7\%) and Papanicolaou (Pap) tests (78.6\%) to transgender men. Willingness to provide routine care decreased with age; willingness to provide Pap tests was higher among family physicians, those who had met a transgender person, and those with lower transphobia. Medical education should address professional and personal factors related to caring for the transgender population to increase access.
\end{abstract}

Ann Fam Med 2018;16:555-558. https://doi.org/10.1370/afm.2298.

\section{INTRODUCTION}

$\eta$ ransgender individuals generally report negative health care experiences and often avoid seeking health care due to fear of discrimination. ${ }^{1}$ Among respondents to the 2015 US Transgender Survey, one-third reported having a negative experience with a health care clinician in the past year, including being asked unnecessary or invasive questions, having to teach their clinician in order to get appropriate care, or being refused transition-related care. ${ }^{1}$ Others have found that Papanicolaou (Pap) test receipt can be particularly uncomfortable for transgender men, ${ }^{2}$ who are less likely to receive routine cervical cancer screening compared to cisgender women. ${ }^{3}$ The current study examines the extent to which primary care clinicians are willing to deliver routine care and Pap tests to transgender patients along with factors that predict willingness.

\section{METHODS}

We surveyed general internal and family medicine clinicians working in a large Midwest integrated health system $(\mathrm{N}=308)$. The survey was conducted using REDCap ${ }^{4}$ in November 2015. Incentives included a $\$ 30 \mathrm{gift}$ card and a chance to receive one of $3 \$ 100$ gift cards.

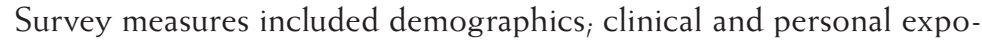
sure to transgender individuals; an item assessing empathy ("It is necessary for a health care practitioner to be able to comprehend someone else's experiences" $)^{5}$ and an 8 -item transphobia scale (adapted from an existing scale). ${ }^{6}$ For questions related to empathy and transphobia, respondents selected from a 7 -point scale ( $1=$ strongly disagree $7=$ strongly agree).

We created 4 questions assessing barriers to providing care to transgender patients. Barriers included a lack of familiarity with transition care guidelines, lack of training in transgender-specific care, lack of exposure to transgender patients, and lack of knowledge about transgender patients among office staff, medical assistants, and/or nursing staff. Another item measured perceptions of being capable of providing routine care to transgender patients. Outcomes included willingness to provide routine care 
Table 1. Clinician Characteristics, Exposure to Transgender Individuals, Barriers and Facilitators Related to Caring for Transgender Patients, and Willingness to Provide Care $(\mathrm{N}=140)$

n (\%)

\section{Clinician characteristics}

Age (mean, SD)

Sex

Male

Female

Continent of origin

North America/Caribbean

Other

Political views

Liberal

Moderate

Conservative

Specialty

Internal medicine

Family medicine

Clinician type

Resident

Advanced practitioner

Attending physician

\section{Exposure}

Ever met a transgender person

Yes

No

Treated transgender patient in past 5 years

Yes

No

Empathy (mean, SD)

Transphobia (mean, SD) ${ }^{a}$

Barriers and Facilitators

Lack of training on transgender health ${ }^{b}$

Yes

No

Lack of exposure to transgender patients

Yes

No

Lack of knowledge about transgender care among staff ${ }^{b}$

Yes

$52(37.1)$

$88(62.9)$

$45(32.1)$

$95(67.9)$

Lack of familiarity with transition care guidelines ${ }^{b}$

Yes

$73(52.1)$

$67(47.9)$

Capable of providing routine care to transgender patients $^{b}$

Yes

No

$44(31.4)$

\section{Willingness to provide care}

Willing to provide routine care for transgender patients ${ }^{b}$

Willing to provide Pap tests for transgender men ${ }^{b}$

Pap $=$ Papanicoulou

a Theoretical range 1-7. Higher score represents greater empathy or transphobia.

b Originally measured on a 7-point scale. Dichotomized for analysis (1-4=no, 5-7=yes). to transgender patients ("I am willing to provide routine medical care to male-to-female/female-tomale transgender patients") and Pap tests to transgender men ("I am willing to perform Pap smears for female-to-male patients"). Questions related to barriers, facilitators, and willingness were measured on a 7 -point scale $(1=$ strongly disagree $7=$ strongly agree) and dichotomized for analysis.

Descriptive analyses, $\chi^{2}$ tests, and $t$-tests were conducted. Multivariable binary logistic regression was used to determine factors predicting willingness (significant variables at the $P<.05$ level in bivariate analyses for at least 1 outcome were included).

\section{RESULTS}

A total of 163 clinicians responded to the survey; 23 were excluded due to missing data (response rate $=53 \%)$. Participant characteristics and other variables are described in Table 1. Overall, $85.7 \%$ and $78.6 \%$ of clinicians were willing to provide routine care to transgender patients and Pap tests to transgender men, respectively. Variables associated $(P<.05)$ with at least 1 outcome were age, continent of origin, specialty, having ever met a transgender person, having cared for a transgender patient in the past 5 years, empathy, transphobia, each of the 4 barriers, and feeling capable of providing routine care (Table 2 ).

In multivariate analysis, the adjusted odds of being willing to provide routine care decreased with age (adjusted odds ratio $[\mathrm{aOR}]=0.89, P$ $=.019$ ) (Supplemental Appendix 1 at http://www. annfammed.org/content/16/6/555/suppl/DC1). The adjusted odds of being willing to provide Pap tests were higher for family physicians than internists $(\mathrm{aOR}=5.08, P=.016)$ and those who had met a transgender person $(\mathrm{aOR}=4.11, P=.032)$, while lower among those with higher transphobia $(\mathrm{aOR}=0.54, \mathrm{P}=.020)$ (Appendix 2, http://www. annfammed.org/content/16/6/555/suppl/DC1).

\section{DISCUSSION}

While most clinicians were willing to provide routine care and Pap tests to transgender patients, support was not universal. Multivariate results suggest that younger clinicians are more willing to provide routine care. Only personal experiences and biases-having met a transgender person and transphobia—predicted willingness to provide Pap tests to transgender men. Our findings, as well as the success of transgender speaker panels, ${ }^{7}$ point to 
Table 2. Factors Associated With Primary Care Clinicians' Willingness to Provide Routine Care for Transgender Patients and Pap Tests for Transgender Men ( $N=140)$

\begin{tabular}{|c|c|c|c|c|}
\hline & \multicolumn{2}{|c|}{ Routine Care for Transgender Patients } & \multicolumn{2}{|c|}{ Pap Test for Transgender Men } \\
\hline & No. (\%) & $P$ Value & No. (\%) & $P$ Value \\
\hline \multicolumn{5}{|l|}{ Clinician characteristics } \\
\hline Age (mean, SD) & & .042 & & .246 \\
\hline Willing & $38.7(13.2)$ & & $39.0(13.4)$ & \\
\hline Not willing & $45.3(13.5)$ & & $42.2(13.3)$ & \\
\hline Sex & & .262 & & .511 \\
\hline Male & 89.7 & & 75.9 & \\
\hline Female & 82.9 & & 80.5 & \\
\hline Continent of origin & & .002 & & .044 \\
\hline North America/Caribbean & 92.3 & & 83.5 & \\
\hline Other & 72.9 & & 68.8 & \\
\hline Political views & & .379 & & .101 \\
\hline Liberal & 89.4 & & 86.4 & \\
\hline Moderate & 80.4 & & 72.5 & \\
\hline Conservative & 87.0 & & 69.6 & \\
\hline Specialty & & .940 & & .020 \\
\hline Internal medicine & 85.6 & & 73.2 & \\
\hline Family medicine & 86.0 & & 90.7 & \\
\hline Clinician type & & .156 & & .165 \\
\hline Resident & 90.4 & & 83.6 & \\
\hline Advanced practitioner & 100.0 & & 100.0 & \\
\hline Attending MD & 79.7 & & 71.9 & \\
\hline \multicolumn{5}{|l|}{ Exposure } \\
\hline Ever met a transgender person & & .020 & & $<.001$ \\
\hline Yes & 89.6 & & 85.8 & \\
\hline No & 73.5 & & 55.9 & \\
\hline Transgender patient in past 5 years & & .022 & & .012 \\
\hline Yes & 92.0 & & 86.7 & \\
\hline No & 78.5 & & 69.2 & \\
\hline \multicolumn{5}{|l|}{ Barriers \& facilitators } \\
\hline Empathy (mean, SD) & & .035 & & .083 \\
\hline Willing & $5.5(1.4)$ & & $5.5(1.3)$ & \\
\hline Not willing & $4.8(1.6)$ & & $4.9(1.8)$ & \\
\hline Transphobia (mean, SD) & & .007 & & $<.001$ \\
\hline Willing & $3.1(1.0)$ & & $3.0(1.0)$ & \\
\hline Not willing & $3.8(1.3)$ & & $3.8(1.1)$ & \\
\hline Lack of training on transgender health & & .240 & & .006 \\
\hline Yes & 82.1 & & 68.7 & \\
\hline No & 89.0 & & 87.7 & \\
\hline Lack of exposure to transgender patients & & .022 & & .013 \\
\hline Yes & 76.9 & & 67.3 & \\
\hline No & 90.9 & & 85.2 & \\
\hline $\begin{array}{l}\text { Lack of knowledge about transgender } \\
\text { care among staff }\end{array}$ & & .018 & & .018 \\
\hline Yes & 75.6 & & 66.7 & \\
\hline No & 90.5 & & 84.2 & \\
\hline Lack of familiarity with guidelines & & .782 & & .027 \\
\hline Yes & 84.9 & & 71.2 & \\
\hline No & 86.6 & & 86.6 & \\
\hline Capable of providing routine care & & $<.001$ & & .043 \\
\hline Yes & 99.0 & & 83.3 & \\
\hline No & 56.8 & & 68.2 & \\
\hline
\end{tabular}


the importance of integrating not only clinical but also personal exposure to transgender individuals into medical education. In addition, family medicine clinicians were more willing than internists to provide Pap tests. Some primary care physicians, however, particularly internists, may not routinely offer these tests, preferring to refer patients to a gynecologist. ${ }^{8}$

Methodological limitations should be noted. Data were collected in 1 health system, thus limiting generalizability. Results may overestimate willingness to care for transgender patients, due to a non-optimal response rate $(53 \%)$ and potential respondent bias. Clinicians who are willing to care for transgender patients may have been more likely to respond. Likewise, social desirability may have positively biased respondents' answers. Finally, our survey did not address clinicians' attitudes towards genderqueer, non-binary, or gender non-conforming individuals, who may experience increased bias in health care settings. ${ }^{9}$

It is encouraging that most respondents reported willingness to provide routine care services to transgender patients. Yet ideally, every clinician should be willing to provide routine care-within the general scope of their practice - to all patients, regardless of their gender identity or expression. Furthermore, willingness is not necessarily equivalent to competence or the ability to provide high-quality, sensitive care; respondents in this study were more likely to report willingness to care for transgender patients than they were to report feeling capable of providing routine care to this patient population. The importance of incorporating best practices for appropriate care for transgender patients into medical education cannot be overstated.

To read or post commentaries in response to this article, see it online at http://www.AnnFamMed.org/content/16/6/555.

Submitted December 12, 2017; submitted, revised, April 12, 2018; accepted June 18, 2018.

Key words: transgender persons; primary health care; Papanicolaou test

Funding support: CSWE/NASW Foundation Social Work HEALS Doctoral Fellowship, funded by the New York Community Trust's Robert and Ellen Popper Scholarship Fund; the Blue Cross and Blue Shield of Michigan Student Award Program; and the Graduate Medical Education Fund at Henry Ford Hospital.

Previous presentations: This study was presented as a paper at the Society for Social Work and Research 21st Annual Conference; January 11-15, 2017; New Orleans, Louisiana.

Acknowledgments: REDCap is a secure, web-based application designed to support data capture for research studies, providing (1) an intuitive interface for validated data entry; (2) audit trails for tracking data manipulation and export procedures; (3) automated export procedures for seamless data downloads to common statistical packages; and (4) procedures for importing data from external sources.

Supplementary materials: Available at http://www.AnnFamMed. org/content/16/6/555/suppl/DC1/.

\section{References}

1. James SE, Herman JL, Rankin S, Keisling M, Mottet LA, Anafi M. The Report of the 2015 U.S. Transgender Survey. Washington, DC: National Center for Transgender Equality; 2016.

2. Peitzmeier SM, Agénor M, Bernstein IM, et al. "It can promote an existential crisis": factors influencing Pap test acceptability and utilization among transmasculine individuals. Qual Health Res. 2017; 27(14):2138-2149.

3. Peitzmeier SM, Khullar K, Reisner SL, Potter J. Pap test use is lower among female-to-male patients than non-transgender women. Am J Prev Med. 2014;47(6):808-812.

4. Harris PA, Taylor R, Thielke R, Payne J, Gonzalez N, Conde JG. Research electronic data capture (REDCap) - a metadata-driven methodology and workflow process for providing translational research informatics support. J Biomed Inform. 2009;42(2):377-381.

5. Kiersma ME, Chen AM, Yehle KS, Plake KS. Validation of an empathy scale in pharmacy and nursing students. Am J Pharm Educ. 2013; 77(5):94.

6. Nagoshi JL, Adams KA, Terrell HK, Hill ED, Brzuzy S, Nagoshi CT. Gender differences in correlates of homophobia and transphobia. Sex Roles. 2008;59(7-8):521-531.

7. Walch SE, Sinkkanen KA, Swain EM, Francisco J, Breaux CA, Sjoberg $M D$. Using intergroup contact theory to reduce stigma against transgender individuals: impact of a transgender speaker panel presentation. J Appl Soc Psychol. 2012;42(10):2583-2605.

8. Cooper CP, Saraiya M. Opting out of cervical cancer screening: physicians who do not perform pap tests. Am J Prev Med. 2014;47(3): 315-319.

9. White Hughto JM, Reisner SL, Mimiaga MJ. Characteristics of transgender residents of Massachusetts cities with high HIV prevalence. Am J Public Health. 2015;105(12):e14-e18. 